\title{
AN EXTENSION OF THE FUGLEDE-PUTNAM'S THEOREM TO CLASS A OPERATORS
}

\author{
Salah Mecheri AND Atsushi UChiyama
}

\begin{abstract}
The familiar Fuglede-Putnam's Theorem is as follows (see [5], [9] and [11]): If $A$ and $B$ are normal operators and if $X$ is an operator such that $A X=X B$, then $A^{*} X=X B^{*}$. In this paper, the hypothesis on $A$ and $B$ can be relaxed by using a Hilbert-Schmidt operator $X$ : Let $A$ be a class $A$ operator and let $B^{*}$ be an invertible class $A$ operator such that $A X=X B$ for a Hilbert-Schmidt operator $X$. Then $A^{*} X=X B^{*}$. As a consequence of this result, we obtain that the range of the generalized derivation induced by this class of operators is orthogonal to its kernel. Some properties of log-hyponormal operators are also given.
\end{abstract}

Mathematics subject classification (2010): Primary 47B47, 47A30, 47B20; Secondary 47B10. Keywords and phrases: Fuglede-Putnam theorem, $p$-hyponormal operator, log-hyponormal operator, class A operator.

\section{REFERENCES}

[1] A. AluthGe, On p-hyponormal operators for $0<p<1$, J. Integral equation and operator theory., 13 (1990), 307-315.

[2] A. Aluthge And D.WANG, An operator inequality which implies paranormality, Math. Inequal. Appl., 2 (1999), 113-119.

[3] T. ANDo, Operators with a norm condition, Acta. Sci. Math (Szeged) 33 (1972), 169-178.

[4] S. K. Berberian, Extension of a theorem of Fuglede and Putnam, Proc. Amer. Math. Soc., 71 (1978), 113-114.

[5] J. B. Conway, Subnormal operators, Research notes in Math., Pitnam Advanced Pub. Program, 51 (1981).

[6] H. K. CHA, An extension of Fuglede-Putnam theorem to quasihyponormal operators using a HilbertSchmidt operator, Youngnam Math. J., 1 (1994), 73-76.

[7] S. L. CAMPell and B. C. Gupta, On k-quasihyponormal operators, Math. Japonica., 232 (1978), $185-189$

[8] M. Cho And T. Huruya, $p$-hyponormal operators, $0<p<\frac{1}{2}$, Comment. Math., 33 (1993), 23-29.

[9] T. FURUTA, Invitation to linear operators, Taylor Francis Inc., 2001.

[10] M. Fuji, C. Himeji AND A. Matsumoto, Theorems of Ando and Saito for p-hyponormal operators, Math. Japonica 39 (1994), 595-598.

[11] P. R. Halmos, A Hilbert space problem book, Spring-Verlag, New York, 1974.

[12] In Ho Jeon, B. P. DugGal, On operators with an absolute condition, J. Korean Math. Soc, 41 (2004), 617-627.

[13] M. Y. LeE AND S. H. LeE, An extension of the Fuglede-Putnam theorem to p-quasihyponormal operator, Bull. Korean Math. Soc., 35 (1998), 319-324.

[14] M. Y. LEE, An extension of the Fuglede-Putnam theorem to $(p, k)$-quasihyponormal operator, Kyungpook Math. J., 44 (2004), 593-596.

[15] S. MeChERI, An extension of the Fuglede-Putnam theorem to p-quasihyponormal operator, Scientiae Math. Japonicae, 62 (2005), 259-264.

[16] R. Schatten, Norm ideals of completely continuous operators, Springer-Verlag, Berlin, 1960.

[17] B. Simon, Trace ideals and their applications, Cambridge. Univ. Press, Cambridge, UK, 1979. 
[18] K. TANahashi, On log-hyponormal operators, Integral equations Operator Theory, 34 (1999), 364 372.

[19] K. TANAHASHI, Putnam's inequality for log-hyponormal operators, Integral equations Operator Theory, 48 (2004), 103-114.

[20] H. TADASI, A note on p-hyponormal operators, Proc. Amer. Math. Soc., 125 (1997), 221-230

[21] A. Uchiyama And K. TANahashi, Fuglede-Putnam's theorem for p-hyponormal or loghyponormal operators, Glasgow Math. J., 44 (2002), 397-410.

[22] A. UCHIYAMA, Berger-Shaws theorem for p-hyponormal operators, Inequalities in operator theory and related topics (Japanese) (Kyoto, 1997). Sürikaisekikenkyūsho Kōkyüroku No. 1027, (1998), 110121.

[23] A. UchiYama, Weyl's theorem for class A operators, Math. Inequal. Appl., 4, 1 (2001), 143-150. 